\title{
Influência dos pais no processo de escolha profissional dos filhos: uma revisão da literatura
}

\author{
Fabiana Hilário de Almeida - Universidade de São Paulo, Ribeirão Preto, Brasil \\ Lucy Leal Melo-Silva1 - Universidade de São Paulo, Ribeirão Preto, Brasil
}

\begin{abstract}
Resumo
Considerando a reconhecida importância da família, sobretudo dos pais, no desenvolvimento vocacional do adolescente, como aponta a literatura, este estudo objetiva contribuir com uma sistematização da produção do conhecimento sobre a influência dos pais no processo de escolha da carreira de filhos adolescentes. Trata-se de um estudo ilustrativo e não representativo. O corpus de análise foi constituído por artigos, livros, teses e dissertações, encontrados em bases eletrônicas de dados e em acervos de universidades. As publicações foram sistematizadas segundo os referenciais teóricos predominantes nos textos analisados. Os resultados mostraram que, independentemente dos referenciais, a influência dos pais ocorre continuamente nos processos de interação dentro dos grupos familiares. Apesar dessa constatação, identificou-se lacuna de estudos sobre intervenções realizadas diretamente com os pais de jovens em processo de escolha da carreira no contexto brasileiro.

Palavras-chave: Escolha vocacional, Orientação profissional, Escolha de carreira, Influência dos pais, Intervenção psicológica.
\end{abstract}

Parental influence on their children's career choice: a literature review

\begin{abstract}
Having in view the importance of family, chiefly parents, in adolescents' vocational development, as seen in the literature, this study aimed at contributing with a systematization of production of knowledge about the influence of parents on their adolescent children's career choice. This is an illustrative, not representative study. The corpus for analysis constituted of papers, books, theses and dissertations found in electronic data bases and university libraries. The publications were systematized according to the prevailing theoretical approaches in the analyzed texts. The results showed that, whatever the approaches are, parental influence occurs continuously in the interaction processes within family groups. Despite this observation, a lack of studies about interventions carried out directly with parents of adolescents in career-choice processes was verified to exist in the Brazilian context.

Keywords: Vocational choice, Vocational guidance, Career decision, Parental influence, Psychological intervention.
\end{abstract}

Considerando a relação dialética estabelecida entre homem e meio, a cada fase da vida humana, da infância à idade madura, diferentes conflitos e demandas permeiam o desenvolvimento da carreira. $\mathrm{O}$ processo da escolha profissional, portanto, encontra-se sobreposto a uma complexa rede de fatores que comporta tanto uma dimensão individual quanto social, envolvendo influências do meio familiar, dos grupos de pares, da formação educacional, do mundo do trabalho e mais amplamente do contexto social, político, econômico e cultural. Todos esses fatores atuam continuamente, influenciando e sendo influenciados pela trajetória vocacional humana.

Tendo em vista que o desenvolvimento de carreira ocorre de modo não linear ao longo da vida, o presente estudo focaliza o processo da primeira escolha profissional na adolescência, período da vida repleto de significativas alterações fisiológicas e psíquicas, bem como em termos de papeis sociais. É nesse contexto de conflitos, ressignificações e readaptações, próprios do processo do adolescer, que a escolha da profissão

\footnotetext{
${ }^{1}$ Endereço para correspondência

Avenida dos Bandeirantes, 3.900

Departamento de Psicologia e Educação/Faculdade de Filosofia, Ciências e Letras de Ribeirão Preto / Universidade de São Paulo. Ribeirão Preto, S.P.

E-mail: psicofabi@usp.br ou lucileal@ffclrp.usp.br
}

representa a primeira grande decisão do adolescente. Tal decisão, sugere Bohoslavsky (2007/1977), implica em reflexões sobre "o que fazer" mas, sobretudo, "quem ser" e "quem não ser". Para o autor, o futuro, no qual o adolescente projeta-se ao escolher, não se caracteriza por ser uma profissão despersonificada, pois ele se imagina como determinada pessoa, com tais atributos, exercendo certa profissão. A tomada de decisão, assim, sustenta-se nas relações interpessoais, especialmente com as figuras parentais, que servem de modelos de comparação e referência. Para o autor, escolher a carreira representa um ensaio para o adolescente, que deve elaborar, antecipadamente, um comportamento futuro.

Indaga-se, entretanto, como o adolescente tem sido influenciado por suas relações familiares na construção de seu projeto de futuro, frente ao instável cenário contemporâneo, caracterizado por um acelerado e significativo processo de transformação das relações humanas e do mundo do trabalho. Destacamse as ressignificações que o modelo de família vem sofrendo, incluindo a vinculação pais e filhos (Romanelli, 1995). A despeito do caráter de transitoriedade próprio da atualidade, Romanelli (2003) aponta que a unidade doméstica, independente da configuração, ainda é o grupo de referência mais importante, sobretudo por meio dos pais, na 
transmissão do capital cultural para orientar os filhos nos processos de socialização e desenvolvimento.

Considerando a influência que os pais exercem sobre o desenvolvimento vocacional dos filhos, mais especificamente sobre o processo da primeira escolha profissional na adolescência, estudos referentes às Teorias de Desenvolvimento de Carreira indicam que o assunto vem sendo abordado por diferentes referenciais teóricos, sob múltiplos focos de análise. Todavia, apesar de as referências datarem da década de 50, para Pinto e Soares (2001), só recentemente o tema é objeto específico de investigação. Duas grandes revisões da literatura foram realizadas sobre o assunto. A primeira, de Schulenberg, Vondracek e Crouter (1984), sobre as investigações até a década de 80 , identificou limites nas pesquisas, já que estas se mantinham centradas em questões sociológicas da família, influenciando o desenvolvimento vocacional dos filhos, ou seja, nos resultados e não na compreensão sobre os processos interacionais que permeiam o desenvolvimento vocacional. A segunda revisão, mais recente, de Whiston e Keller (2004), para publicações de 1980 a 2002, observou uma carência de estudos com características longitudinais que se propusessem a investigar o tema em sua complexidade.

Com o presente estudo, objetiva-se, portanto, contribuir com a produção do conhecimento sobre a temática da "influência dos pais no processo de escolha da carreira de filhos adolescentes", por meio de uma análise ilustrativa e não representativa, na qual o corpus de investigação é composto por trabalhos publicados em revistas científicas, livros, anais de congressos e teses/dissertações. Espera-se, através da sistematização dos achados da amostra de investigações analisadas estimular novas pesquisas visando à implementação e à avaliação de processos de intervenção junto a pais.

\section{Percurso metodológico}

Um levantamento da literatura da área da Orientação Vocacional/Profissional e das Teorias de Desenvolvimento de Carreira foi realizado objetivando mapear a produção de parte do conhecimento. Esse procedimento de coleta ocorreu em três frentes de buscas: (1) Bases de dados eletrônicas: ScienceDirect, Web of Science, ERIC, Medline, Lilacs, Index Psi, Psicodoc, PsycINFO, Scielo e Portal Capes (Banco de testes), por meio das palavras-chave: vocational guidance, career theory, career development, vocational choice, professional choice, career choice, career exploration, career indecision, cruzadas com: parents, parental influence, parental involvement, parenting style, psychological separation, attachment, com delimitação para publicações do período de 1950 a 2009; (2) Recursos do Google Scholar para ampliar as bases de dados em relação às publicações em livros e teses/dissertações; (3) Acervos catalogados nas bibliotecas da Faculdade de Filosofia, Ciências e Letras da Universidade de São Paulo (FFCLRP-USP) no Brasil e do Instituto de Orientação Profissional (IOP) da Universidade de Lisboa e da Faculdade de Psicologia da Universidade do Porto, em Portugal.

Concomitantemente às pesquisas nas diferentes fontes, o material extraído foi imediatamente filtrado pelo pesquisador, em virtude do volume de publicações não centradas, especificamente, na influência parental sobre o processo da escolha profissional dos filhos adolescentes. A seguir, os estudos foram organizados em função das datas e veículos de publicação ou divulgação, como mostra a Tabela 1.

Tabela1 - Distribuição das publicações em função da data e natureza de publicação

\begin{tabular}{lcccccc}
\hline Período & $\begin{array}{c}\text { Artigos } \\
\text { científicos }\end{array}$ & $\begin{array}{c}\text { Teses/ } \\
\text { dissertações }\end{array}$ & Livros & $\begin{array}{c}\text { Capítulo } \\
\text { de livros }\end{array}$ & $\begin{array}{c}\text { Publicações } \\
\text { em anais }\end{array}$ & Total \\
\hline $1950-1959$ & 1 & - & - & - & - & 1 \\
$1960-1969$ & - & - & - & - & - & - \\
$1970-1979$ & - & - & 1 & - & - & 1 \\
$1980-1989$ & 5 & - & - & - & - & 5 \\
$1990-1999$ & 5 & 2 & 1 & 4 & 1 & 13 \\
$2000-2009$ & 15 & 1 & - & 8 & 2 & 45 \\
\hline Total & 26 & 3 & 2 & 12 & \\
\hline
\end{tabular}

Como destacaram Pinto e Soares (2001), foi a partir da década de 90 que o interesse sobre a temática surgiu com maior intensidade, dobrando na primeira década do milênio. Após uma primeira imersão nos dados, para este estudo organizou-se uma distribuição da amostra ilustrativa dos trabalhos selecionados, que tratam da influência dos pais na escolha da carreira dos filhos. Os trabalhos foram lidos e organizados em cinco categorias de análise, conforme os referenciais teóricos explícitos, predominantes ou segundo inferência dos autores do presente estudo, com base 
nas concepções e referências dos textos que constituíram o corpus de análise do estudo.

\section{Resultados e Discussão}

Os dados são apresentados e discutidos segundo os referenciais teóricos que sustentam os percursos metodológicos, não seguindo necessariamente uma organização cronológica das publicações na análise. São eles: (1) psicodinâmico, (2) desenvolvimentista contextualista, (3) sistêmico, (4) construtivista e (5) sócio-cognitivo. O Anexo 1 apresenta a distribuição das publicações segundo os referenciais teóricos em função de: data, tipo, autoria e título da publicação.

\section{Referencial psicodinâmico}

As primeiras pesquisas a investigar as influências dos pais no processo da escolha vocacional dos filhos foram desenvolvidas, na década de 1950, por Anne Roe, com referencial psicodinâmico. A autora relacionou o comportamento vocacional às primeiras experiências da infância, sugerindo a importância das práticas educativas familiares como modelos de satisfação/frustração para os filhos, determinando a força de suas necessidades (Roe, 1957). Ancorou-se em conceitos de Maslow, como as necessidades inferiores (segurança e conforto) e as necessidades superiores (autonomia e afirmação) para compreender como estas influenciavam o desenvolvimento da personalidade, incluindo o comportamento vocacional. As análises, no entanto, não concluíram como as experiências precoces $\mathrm{da}$ criança convertiam-se em motivadores inconscientes, culminando com a escolha vocacional. Observa-se, desse modo, que a autora enfatizava as influências ocorridas nas relações familiares de modo unilateral, isto é, dos pais para os filhos, dando pouca importância à reciprocidade ocorrida nos processos de interação. Segundo Guichard e Huteau (2001), autores da área consideram que essa teoria foi insuficientemente explorada na época, fomentando poucos estudos empíricos. Cabe destacar, entretanto, tendo em conta o momento histórico, a originalidade de suas pesquisas no que diz respeito aos estudos da área.

Na década de 70, Bohoslavsky (2007/1977), psicólogo argentino de grande influência no contexto latinoamericano, pautando-se em conceitos como identificação e reparação, retomou a análise das relações gratificadoras/frustradoras da criança com o grupo familiar, traduzindo-se em identificações conscientes ou inconscientes que influenciam a decisão vocacional. A família, como um grupo com conceitos próprios e sua dinâmica de relações, exerce participação no desenvolvimento vocacional dos filhos e, assim, para o autor, as práticas em orientação profissional devem considerar a percepção valorativa que o grupo familiar tem das ocupações, como também a problemática vocacional dos membros, já que satisfações/insatisfações dos pais influenciam os filhos desde a infância. A escolha da profissão pelo adolescente, segundo o autor, simboliza o momento em que filho aceita crescer e, assim, desestrutura o grupo familiar, já que anuncia seu processo de separação. Essa situação pode despertar sentimentos de culpa no adolescente. No entanto, ao mesmo tempo em que o filho desestabiliza a estrutura familiar ao escolher a profissão, ele pode assumir o papel de "reparador" do grupo, possibilitando uma nova configuração, mudanças no vínculo pais-filhos e projetos de futuro mais autônomos. Identifica-se, assim, que Bohoslavsky (2007/1977) avançou em relação aos estudos anteriores, uma vez que considerou o papel das interações e influências recíprocas entre pais e filhos. Assinala-se que suas concepções sustentam várias pesquisas e práticas desenvolvidas na área no Brasil.

Refletindo sobre a psicodinâmica subjacente ao processo da escolha, Dias (1995) assinalou a importância da inclusão da familia nos atendimentos de orientação profissional, uma vez que os pais têm se mostrado muito ansiosos no momento da decisão do filho, pois revivem seus próprios dilemas quanto à escolha e, dependendo da maneira como lidam com tais questões, oferecerão ou não continência às ansiedades dos filhos na fase de decisão. O modo como os pais lidam com suas problemáticas vocacionais também foi abordado por Soares-Lucchiari (1997a), ao tratar sobre os papeis que a família distribui aos filhos, que se tornam depositários das necessidades parentais, e sobre os mecanismos psicológicos utilizados pelos adolescentes para lidarem com os sonhos dos pais. A autora conclui, considerando a necessidade das intervenções em orientação profissional abordarem os mecanismos inconscientes implicados na problemática vocacional, uma vez que só assim tornar-se-á possível ao filho realizar uma escolha menos conflituosa e integrada às suas condições psíquicas (Soares-Lucchiari, 1997b). Em publicação recente, Soares e Knabem (2005) propuseram um programa de orientação profissional intensivo com adolescentes, no qual foram incluídas duas reuniões com pais, a fim de favorecer o diálogo entre pais e filhos.

Considerando que o meio familiar embasa a estruturação da personalidade ocupacional, para Andrade (1997), a família através da transmissão de conceitos, mitos e valores, pode influenciar tanto contribuindo para a decisão profissional dos filhos como, por outro lado, 
sendo impeditiva de um processo de escolha autônomo. O autor alerta para cobranças dos pais, por vezes declaradas e, em outros momentos, sutis e veladas, ressaltando que quando o vínculo pais-filhos é harmonioso e verdadeiro, as opiniões parentais são valorizadas e até aceitas, sem a mera submissão dos adolescentes e, então, a família é sentida como fonte de apoio e sustentação. $\mathrm{O}$ autor também reflete a escolha profissional representar a intensificação do processo de separação pais-filhos, sendo que decidir pela profissão é acelerar esse processo. Pais, mesmo desejosos do crescimento dos filhos, podem viver com angústia esse período de separação, que nem sempre é só de ordem afetiva, pois muitos adolescentes vão estudar em outra cidade.

$\mathrm{Na}$ mesma direção, Pompermayer (1999) analisou autobiografias de adolescentes em orientação profissional, relacionando o processo da escolha da profissão com o luto que os filhos devem realizar em relação às imagos parentais infantis. A autora identificou tanto a decepção que os adolescentes sentem pela desestabilização das figuras parentais que antes eram idealizadas, como também a importância de tal processo influenciando-os a realizarem investimentos futuros como, por exemplo, a escolha da carreira.

Refletindo também sobre a transição do adolescente à vida adulta, Oliveira (2005) analisou os efeitos dos sentimentos das mães (frente ao processo de separação/individuação dos filhos) sobre a escolha profissional dos adolescentes. Os pais, segundo a autora, mostram-se inseguros frente à escolha da carreira dos filhos e que tal ansiedade despertada nos pais repercute na decisão dos adolescentes. Quando este caminha em direção à autonomia, muitos pais sentem perder sua função e sofrem, ao sentir que não possuem mais o controle sobre o filho. A autora salientou que a condição para o adolescente tornar-se autônomo depende não só da qualidade do vínculo pais-filhos e da capacidade dos pais serem modelos identificatórios adequados, mas também de tolerarem e estimularem a separação psicológica dos filhos em direção ao mundo adulto. Em outra publicação, Oliveira e Dias (2001) discutem sobre repercussões das novas configurações familiares sobre os projetos vocacionais dos adolescentes, incluindo a escolha da profissão. As autoras concluem que os pais têm revelado dificuldades acerca do exercício de seus papéis, e alertam para a ausência de modelos adequados aos processos de identificação dos filhos, o que repercute sobre um trajeto profissional autônomo por parte do adolescente.

Investigando também sobre a psicodinâmica das relações pais-filhos influenciando processos de escolha,
Levenfus e Nunes (2002a) identificaram que, adolescentes com perda parental apresentavam questões que os remetiam à perda da figura de referência e que necessitavam ser elaboradas, para que lhes fosse possível investir psiquicamente na escolha profissional. Já a respeito das influências da separação conjugal sobre os filhos, as autoras destacam as mudanças que a família vem sofrendo e que se refletem sobre a escolha dos adolescentes, já que a "saída" de um membro ou mesmo a "entrada" de novos no grupo familiar, repercutem em seus processos identificatórios, influenciando as escolhas vocacionais (Levenfus \& Nunes, 2002b). Na terceira parte da pesquisa, dados sobre as influências da ansiedade de separação pais-filhos no momento da escolha, indicaram que os jovens que apresentavam dificuldades quanto ao processo de separação-individuação revelavam muita indecisão, problemas para discriminar seus aspectos internos, as profissões entre si e para realizarem explorações vocacionais (Levenfus \& Nunes, 2002c).

Tendo em conta que as investigações sobre a influência dos pais na escolha da carreira dos filhos, ao longo da história, visam a contribuir com o delineamento de estratégias de intervenção, destaca-se um conjunto de estudos que aborda intervenções com pais no contexto brasileiro. Inicialmente, Duarte, MeloSilva, Santos e Bonfim (2005) investigaram: as expectativas das mães com relação ao processo de orientação profissional de seus filhos; quanto à escolha da carreira dos adolescentes; e quanto as suas percepções acerca da influência da família. As conclusões enfatizam que as expectativas dos pais sobre o processo de escolha profissional dos filhos, necessitam ser consideradas pela área, salientando a importância de intervenções com os pais, oferecendolhes espaços de acolhimento e reflexão sobre a escolha da profissão demarcar a entrada dos adolescentes no mundo adulto, cabendo aos pais o papel de instigá-los no processo de desenvolvimento rumo à autonomia. Outra investigação de Melo-Silva, Silva e Venturini (2005) constatou lacunas na comunicação entre pais e filhos, quando o adolescente vivencia o processo da escolha profissional. Dados mostram que, quando há comunicação e compreensão de ambas as partes e um maior posicionamento dos pais, isso favorece que os filhos fiquem mais seguros para escolher. Esses achados fomentaram o estudo (Almeida, 2009), no qual se desenvolveu um programa de intervenção com pais, com base na técnica de grupo operativo. Os dados apontam que os pais investem na formação educacional dos filhos para que escolham a profissão e ingressem no Ensino Superior, revelando grandes expectativas em relação ao futuro profissional deles. Entretanto, apresentam dificuldades para assumir a influência exercida sobre o processo da escolha dos 
adolescentes e para se posicionar com diálogos e situações facilitadoras do desenvolvimento vocacional, por receio de influenciá-los negativamente. Com a intervenção, os pais revelaram conflitos e contradições em suas posturas, denunciando ambivalência de sentimentos frente à progressiva independência dos filhos, e o desejo de postergar a separação pais-filhos. A técnica de grupo operativo favoreceu aos pais um maior conhecimento de seus sentimentos e assunção de papeis, acarretando em mudanças no vínculo paisfilhos, em relação ao processo de escolha profissional. A investigação ressaltou a importância de serem realizados mais estudos de intervenção com pais de adolescentes em fase de escolha, tendo em conta a instabilidade do cenário contemporâneo, envolvendo as relações familiares e o mundo do trabalho.

O referencial psicodinâmico, assim, introduziu o tema na pauta das investigações da área, na metade do século passado. Particularmente no Brasil, observase grande influência desse referencial, após a década de 1970 com Rodolfo Bohoslavsky. As críticas tradicionais apontam para limitações do referencial por centrar-se apenas condições internas de quem "escolhe". Entretanto, o que se evidencia é que as publicações ressaltam a importância de se compreender aspectos psicodinâmicos (incluindo mecanismos inconscientes) que permeiam a relação entre pais e filhos e que mantêm influência sobre um processo da escolha profissional autêntico e autônomo pelos adolescentes e, conseqüentemente, sobre a progressiva inserção destes no universo adulto e mundo do trabalho. O referencial, portanto, tem considerado influências da ordem das instituições familiares, educacionais e de produção, como apontou Bohoslavsky (2007/1977). Pode-se observar, portanto, que das quinze publicações selecionadas, três sugerem a importância de realização de intervenção com pais.

\section{Referencial desenvolvimentista contextualista}

A partir de 1984, destacaram-se estudos coordenados por Vondraceck, embasados na Teoria Ecológica de Bronfenbrenner que compreendem o desenvolvimento humano como construção contínua entre indivíduo e meio, ambos em constante processo de mudança (Vondracek, 2004). Pesquisando acerca da influência parental no desenvolvimento vocacional, Schulenberg, Vondracek, e Crouter (1984) observaram que as pesquisas até então realizadas desconsideravam os processos de interação mútua homem-meio que estão envolvidos no desenvolvimento vocacional, repercutindo sobre as decisões de carreira. Pela perspectiva desenvolvimentista contextualista, o contexto familiar é entendido como o microssistema do indivíduo, onde ambos se influenciam reciprocamente.
Assim, as expectativas, aspirações, explorações e decisões profissionais dos filhos serão constantemente influenciadas pelo contexto familiar (SchmittRodermund \& Vondracek, 1999). Os valores dos pais, inclusive, exercem mais influência sobre $\mathrm{O}$ desenvolvimento vocacional dos filhos, incluindo o processo de escolha, do que os grupos de pares e a formação escolar (Hartung, Porfeli \& Vondracek, 2005). Os estudos coordenados por Vondracek ofereceram contribuições valiosas ao campo da Orientação Vocacional/Profissional sobre o assunto, influenciando outros referenciais teóricos.

Há repercussões deste referencial na pesquisa de Otto (2000) que analisou a percepção dos adolescentes acerca das influências dos pais na progressão de suas carreiras. $\mathrm{O}$ autor constatou que entre todas as pessoas às quais os filhos recorriam a fim de serem auxiliados em seus planos de carreira, as figuras parentais foram as mais citadas, sobretudo as mães, uma vez que elas têm maior conhecimento dos interesses e competências vocacionais dos filhos. O autor conclui enfatizando a importância de os profissionais, a fim de aumentar a eficácia das intervenções, trabalharem mais com pais, de modo que estes auxiliem positivamente seus filhos a tomarem decisões de carreira.

Nota-se que os estudos embasados nesse referencial, considerando as influências recíprocas e em constante processo de mudança entre homem e meio, sugerem a importância do papel favorecedor que a família, sobretudo os pais, pode exercer nos planejamentos de carreiras dos filhos, incluindo a escolha profissional.

\section{Referencial sistêmico}

Por sua vez, as pesquisas sistêmicas investigam a influência parental no processo da escolha profissional por meio da análise da complexidade das dinâmicas familiares, pautando-se em conceitos como apego parental e separação psicológica da Teoria do Attachment de Bowlby e englobando a noção de identidade, formulada por Erikson. Por essa perspectiva, estudos cujo foco relaciona conflitos conjugais e indecisão profissional de adolescentes, identificaram que as famílias estruturadas (menos rígidas e flexíveis) que fomentam $\mathrm{o}$ investimento vocacional sem imposição de metas incompatíveis com os recursos dos filhos, são favorecedoras da exploração vocacional, na facilitação do processo da escolha. Por outro lado, meios que não oferecem apoio, balanceados com situações de desafio, não contribuem com a autonomia dos filhos em relação aos seus projetos vocacionais (Eigen, Hartman \& Hartman, 1987; Lopez \& Andrews, 1987). Investigando também possíveis efeitos do 
divórcio parental na indecisão de carreira dos adolescentes, Scott e Church (2001) observaram que aqueles provenientes de famílias com maior estabilidade demonstravam maiores recursos para tomar decisões quanto à carreira que os provenientes de grupos familiares com histórico de divórcio. Remetendo-se também à indecisão profissional, Lopez (1989) observou que não apenas os filhos, mas também os pais mostram-se ansiosos por estarem envolvidos afetivamente no momento da escolha sendo que, dependendo do nível de ansiedade, tal situação pode prejudicar o processo da separação psicológica paisfilhos e até a construção de projetos autônomos de carreira, a começar pela escolha profissional.

$\mathrm{Na}$ década de 90, destacaram-se estudos que também analisaram a influência dos relacionamentos familiares no desenvolvimento da carreira em adolescentes, como a pesquisa de Blustein, Walbridge, Friedlander e Palladino (1991), que examinou o grau de separação psicológica e o apego parental correlacionados ao compromisso com a escolha da profissão e a tomada de decisão. Os resultados confirmaram que quando o vínculo pais-filhos é seguro e oferece condições para uma separação psicológica saudável com as figuras parentais, isso se correlaciona positivamente com explorações e investimentos vocacionais mais intensos pelos adolescentes e, ainda, que são menores as chances de assumirem projetos vocacionais outorgados por outros. Os autores também apontaram a necessidade de realização de programas de intervenção juntos a pais e adolescentes, de modo a melhorar a qualidade da relação em termos de comunicação, orientação e educação.

Merecem referência as pesquisas de O'Brien (1996) e O'Brien, Friedman, Tipton e Linn (2000) que também investigaram a influência do apego e da separação psicológica com os pais na construção de carreira de mulheres adolescentes. Os dados revelaram que as jovens que experenciaram o apego com a mãe e que se direcionavam para uma maior independência, interessavam-se em seguir uma carreira compatível as suas capacidades e que, inclusive, sentiam-se altamente eficazes em relação a essas escolhas. Ademais, as adolescentes identificavam que, mais do que a figura paterna, as mães mostram-se mais presentes $\mathrm{e}$ envolvidas no processo da escolha profissional, apoiando ou conversando sobre seus projetos vocacionais. Kracke (1997) também constatou que a relação de proximidade entre pais e filhos, não autoritária e que inclui apoio e ações dos pais em direção à exploração vocacional dos adolescentes, tem influência direta na exploração mais intensa por parte dos filhos no período da escolha e, em uma maior autonomia dos adolescentes.
No que diz respeito à influência do apego com a mãe, da ansiedade do adolescente (medo da escolha errada, medo de desapontar os pais) e do estilo parental sobre o processo de exploração de carreira para a tomada de decisão, Vignoli, Croit-Belz, Chapeland, Fillipis e Garcia (2005) observaram que para as meninas, a ansiedade geral e o estilo parental negligente relacionaram-se negativamente com a exploração de carreira e, por outro lado, o apego seguro com a mãe e o medo de falhar relacionaram-se positivamente; já os meninos, o receio de desapontar os pais relacionou-se positivamente com o processo de exploração da carreira.

Entre as publicações sistêmicas no Brasil, menciona-se investigação de Destri (1996) que relacionou o processo da escolha profissional com a autonomia/individuação do adolescente. Os dados revelaram predominância de uma ideologia individualista nos filhos, que afirmam que os pais não devem ter participação na escolha ou que a influência deve ser apenas de apoio, no sentido de aceitação de suas escolhas. A maioria, inclusive, salientou que as mães apoiam mais suas decisões que os pais. A autora reflete criticamente apontando que os adolescentes não querem ser questionados no momento de insegurança, frente às decisões que devem tomar quanto à escolha, sobretudo, quando se trata do posicionamento das figuras parentais significativas. Também refletindo sobre a vivência do adolescente em relação à primeira escolha profissional, Filomeno (1997) trata sobre seus conflitos, dificuldades, angústias, medos e pressões sofridas, analisando também como os mitos e crenças familiares influenciam nesse processo. Para a autora, na escolha profissional estão embutidas regras, mitos, o papel que o jovem exerce na família, bem como as expectativas atribuídas a ele.

A partir das onze publicações destacadas, identifica-se que o referencial sistêmico contribuiu por considerar cada vez mais a influência da complexidade das relações familiares e da importância da qualidade da vinculação pais-filhos sobre os processos da escolha profissional dos adolescentes, tanto no sentido de favorecer uma escolha realística e autônoma, quanto de limitar, contribuindo para a indecisão profissional ou assunção de projetos outorgados por outras pessoas, constituindo-se assim grande avanço na produção do conhecimento sobre o tema.

\section{Referencial construtivista}

Integrando contribuições desenvolvimentistas contextualistas e sistêmicas, Young propôs a Teoria da Ação em Contexto, na qual a carreira é entendida como um comportamento intencional $e$ dirigido de carreira, construída socialmente, isto é, conjuntamente entre 
homem e contexto. O meio familiar é o grande facilitador da exploração e do investimento vocacional dos filhos, sendo que pais e filhos devem se envolver em ações conjuntas, por meio de processos direcionados ao alcance de objetivos. Destaca-se, assim, investigação de Young, Friesen e Borycki (1994) que constatou a influência parental no desenvolvimento de carreira dos filhos por meio das narrativas vocacionais dos adolescentes em processo de escolha, o que sugeriu aos autores que o grande sustentáculo dos projetos vocacionais dos jovens é a comunicação pais e filhos. Sob essa perspectiva de análise, Young e colaboradores (2001) investigaram como são construídos os projetos vocacionais dentro dos grupos familiares, ou seja, como ocorrem os processos de interação pais-filhos, envolvendo conversas e ações conjuntas e bidirecionais orientadas para a construção das trajetórias vocacionais dos adolescentes. Observou-se que cada vez mais os pais reconhecem a importância de suas participações junto aos filhos, em termos de investimentos e apoio, favorecendo-lhes seus percursos e tomadas de decisão vocacional. Famílias "mais ativas", onde há diálogo, onde se mesclam situações ora de desafio, ora de apoio, favorecem mais a construção de projetos conjuntos entre pais e filhos do que grupos familiares "menos ativos".

Palmer e Cochran (1988) também observando que os pais muitas vezes identificam a influência que exercem sobre os processos de decisão sobre carreira dos filhos e que até gostariam de cumprir papel mais ativo na orientação deles, realizaram um estudo de intervenção no qual testaram a efetividade de um programa realizado com pais a fim de ajudá-los a orientar seus filhos. Os resultados apontam que os adolescentes apresentaram melhora acentuada no desenvolvimento de carreira, além do fortalecimento do vínculo parental. As conclusões revelam que as figuras parentais podem funcionar de forma eficaz na promoção do desenvolvimento da carreira dos filhos, mas que, no entanto, são necessárias mais investigações que realizem programas junto aos pais de adolescentes em processo de escolha. Destaca-se, assim, que este foi estudo de natureza interventiva e avaliativa com pais.

Com a mesma perspectiva, examinando variáveis do contexto familiar (coesão e expressividade, conflito, orientação para sucesso) podem se associar às variáveis do desenvolvimento vocacional dos filhos (exploração, investimento e tendência), Gonçalves (1998) identificou que o meio familiar facilita o desenvolvimento vocacional e, consequentemente, tomadas de decisão, quando este é um contexto de apoio, desafio e promove autonomia dos filhos. Por outro lado, pode obstaculizar o desenvolvimento vocacional ao se mostrar como meio aglutinado (pouca diferenciação e autonomia entre os membros), radicalmente competitivo, negligente e rígido. Mais recentemente, Gonçalves e Coimbra (2007), através de entrevistas com adolescentes e pais, investigavam qual o papel ativo dos pais em termos de apoio junto aos filhos no momento da escolha vocacional, e também como os estes experimentavam essa influência. Os dados corroboram a influência dos pais no delineamento das trajetórias vocacionais dos adolescentes, sendo que a qualidade dos projetos tem relação com possibilidades que os contextos familiares viabilizam aos filhos, sobretudo a respeito do apoio emocional e material. Observaram progressivo envolvimento e intencionalidade dos pais para apoiarem os filhos na construção de projetos, principalmente, quando os adolescentes necessitam realizar a escolha da formação. Por outro lado, a qualidade e intensidade desse apoio variam em função da escolaridade e do nível profissional dos pais. O estudo enfatizou a importância da implementação e avaliação de projetos de intervenção que incorporem contextos decisivos como a família, já que esta pode proporcionar um meio facilitador de oportunidades, experiências e apoios qualificados, transformando o grupo familiar em agente dinâmico do desenvolvimento vocacional.

Nessa direção, destacam-se pesquisas de Pinto e Soares $(2001,2002)$ e Soares e Pinto (2004) que culminaram com programas de intervenção com pais. As autoras observaram que os pais portugueses reconhecem-se como agentes importantes no desenvolvimento vocacional dos filhos, ensaiando diálogos e oportunizando atividades com finalidade de auxiliá-los no processo da escolha profissional. Assim, as pesquisadoras coordenam intervenções com pais, ancoradas em três eixos de abordagem: a comunicação estabelecida com os filhos referente ao desenvolvimento vocacional, atividades praticadas entre pais e filhos, e expectativas dos pais em relação ao futuro dos filhos. Tais pesquisas também enfatizam a necessidade do envolvimento dos pais nas práticas de orientação profissional, através de metodologias de intervenção.

Observando por diferentes vértices, Carvalho e Taveira (2009) exploraram a visão de alunos, pais, professores e profissionais de orientação profissional sobre o papel dos pais no processo de implementação das escolhas de carreira dos filhos. $O$ estudo identificou que os grupos foram unânimes no reconhecimento da importância das figuras parentais em relação à fase da tomada da decisão e revelaram que os pais devem contribuir para o desenvolvimento e implementação de escolhas de carreira, por meio de 
condutas que envolvam comunicação, apoio e acompanhamento dos filhos. Tal apoio deve sustentarse em dupla vertente, afetiva e instrumental, isto é, incentivo e compreensão/aprovação das escolhas/ações dos filhos, como também em relação ao auxílio instrumental para resolução de problemas e concretização de opções, promovendo atividades que oportunizem aos adolescentes a exploração de seus meios.

Evidencia-se, portanto, pelas dez pesquisas destacadas, que o referencial construtivista, apoiado na concepção da construção conjunta (pais e filhos) de projetos vocacionais, favoreceu a compreensão de como a participação dos pais pode ser efetiva (incluindo diálogos, ações, apoio), contribuindo para o desenvolvimento vocacional, consequentemente, para o processo da escolha profissional. Para isso, os estudos enfatizam a importância da realização de intervenções com pais.

\section{Referencial sócio-cognitivo}

A Teoria Sócio-Cognitiva da Carreira de Albert Bandura compreende o desenvolvimento ancorado em três fatores de interação: comportamento, meio e pessoa. O modo como o homem relaciona-se com a escolha da profissão tem origem em suas experiências anteriores no meio familiar. Um dos conceitos centrais da teoria de Bandura refere-se ao sentimento de competência (auto-eficácia), o qual se define como o conjunto de crenças que o mesmo possui acerca de suas capacidades para realizar determinadas atividades (Guichard \& Huteau, 2001). Com base nessas concepções, Bandura, Barbaranelli, Caprara e Pastorelli (2001) testaram as redes de influências sócio-cognitivas sobre as aspirações de carreira e trajetórias de adolescentes e observaram o impacto das crenças de auto-eficácia dos pais e de suas aspirações em relação à eficácia das escolhas de carreiras dos filhos. Nessa linha, Lent e colaboradores (2002) analisarem as percepções de adolescentes sobre as influências em relação às opções de carreira e execução de suas escolhas, e constataram que os pais influenciam os filhos promovendo recursos, oportunidades e vivências favoráveis às trajetórias de carreira dos adolescentes.

No cenário brasileiro, pautando-se no referencial sócio-cognitivo e em contribuições desenvolvimentistas, Bardagi e Hutz (2006) embasados na teoria Tipológica de Baumrind sobre os padrões de interação familiar, abordaram a influência dos estilos parentais sobre a indecisão profissional, ansiedade e depressão em adolescentes. Identificaram-se correlações positivas entre essas variáveis, observando que filhos de pais negligentes apresentaram os piores escores nas três medidas. Observou-se que os estilos parentais afetam o desenvolvimento dos filhos, inclusive na formação de competências básicas que influenciarão comportamentos como a tomada decisão da carreira. Tais dados corroboram a influência dos estilos parentais sobre o bem-estar psiquíco dos jovens e reiteram a importância da inclusão da família nos processos de orientação vocacional. Em outra pesquisa, Bardagi e Hutz (2008) realizando entrevistas com adolescentes que abandonaram a graduação, observaram que na percepção dos participantes sobre o apoio parental, não havia diálogo aberto no cotidiano familiar sobre a complexidade do processo da escolha profissional e sobre a transição escola-universidade, sendo que as conversas familiares versavam sobre vestibular e a definição do curso superior. Assim, apesar de o estudo constatar que os pais são as figuras mais significativas em relação ao processo da escolha profissional dos filhos, não há, muitas vezes, uma comunicação sistemática sobre o tema, o que alerta mais uma vez para a necessidade de programas interventivos que promovam a aproximação entre pais e filhos nos processos de orientação vocacional.

Observa-se que as publicações sócio-cognitivas sobre o tema são recentes, datando da última década. Por meio delas, compreende-se que o papel da família no processo da escolha profissional, de modo geral, está ligado à aquisição de sentimentos de auto-eficácia pelos filhos, o que irá influenciar diretamente suas percepções de futuro, expectativas de soluções de problemas e desempenhos na tomada da decisão.

\section{Considerações finais}

O panorama sobre as publicações da área, segundo diferentes referenciais teóricos, revela que a influência dos pais nos processos da escolha profissional dos filhos ocorre continuamente nos processos de interação dentro dos grupos familiares, algo iniciado na infância. A influência envolve tanto ações objetivas e práticas, como intervenções dos pais proporcionando: apoio financeiro, formação educacional, diálogos/ações facilitadoras da exploração vocacional; como também influências de ordem subjetiva, nem sempre tão claras e, por vezes, inconscientes, como: apoio, aprovação/reprovação das escolhas, expectativas de resultados, cobranças e, até mesmo, influências dos estilos de interação familiar, valores/crenças dos pais sobre mundo do trabalho, suas problemáticas vocacionais, sonhos e projetos que mantêm para os filhos, dificuldades no processo de separação pais-filhos, dentre outros. Todas essas variáveis de influência atuam, possibilitando ou mesmo limitando o desenvolvimento vocacional dos filhos e, mais particularmente, o processo da escolha da carreira. 
A despeito de cada publicação privilegiar a análise das variáveis que apresentam correspondência com os referenciais teóricos que as subsidiam, constata-se progressão nas pesquisas na tentativa de ampliar a compreensão da influência dos pais nos processos da escolha profissional dos filhos. Assim, se inicialmente os estudos investigavam se os pais exerciam tal influência e, depois, como esta se processava, mais recentemente, as investigações reconhecem a participação familiar e ressaltam a necessidade de realização de intervenções com pais, de modo que estes se tornem agentes favorecedores do desenvolvimento vocacional dos filhos. Enfatiza-se, todavia, como fora observado, que a área carece de estudos sobre avaliação de programas com os pais de adolescentes em processo de escolha da profissão, como assim o fizeram Palmer e Cochran (1988), Pinto e Soares (2002) e Soares e Pinto (2004) e, no Brasil, Almeida (2009). Assim, abordar o papel dos pais no processo da escolha profissional dos filhos, transcende tratar o assunto com o adolescente, sendo necessária a intervenção com as figuras parentais, valendo-se dos estudos desenvolvidos sobre o tema, e considerando as significativas mudanças que vêm ocorrendo no mundo contemporâneo, e consequentemente, no mundo do trabalho e nas relações familiares.

Os processos de intervenções com pais podem contribuir para a produção do conhecimento acerca da qualidade emocional do vínculo pais-filhos, e gerar condições facilitadoras do processo da escolha da carreira e do desenvolvimento do jovem em direção ao mundo adulto, como revelaram estudos mencionados. Savickas (1995) analisa que o distanciamento que muitas vezes ocorre entre a teoria e a prática nos domínios da Orientação Vocacional/Profissional e de carreira é sempre tema de muitas discussões e questionamentos. Assim sendo, linhas investigativas articulando teoria e intervenção, sob diferentes perspectivas, mostram-se extremamente significativas, sobretudo no contexto brasileiro.

\section{Referências}

Almeida, F. H. (2009). Orientação de pais com filhos em processo de escolha profissional: uma intervenção em grupo operativo. Dissertação de Mestrado, Faculdade de Filosofia, Ciências e Letras, Universidade de São Paulo. São Paulo.

Andrade, T. D. (1997). A família e a estruturação ocupacional do indivíduo. Em Levenfus, R. S. (Org.). Psicodinâmica da escolha profissional (pp. 123134). Porto Alegre: Artes Médicas.

Bandura A.; Barbaranelli, C.; Caprara, G. V. \& Pastorelli, C. A. (2001). Self-efficacy beliefs as shapers of children's aspirations and career trajectories. Child Development, 72 (1), 187-206.

Bardagi, M. P. \& Hutz, C.S. (2006). Indecisão profissional, ansiedade e depressão na adolescência: a influência dos estilos parentais. Psico-USF, 11 (1), 65-73.

Bardagi, M.P. \& Hutz, C.S. (2008). Apoio parental percebido no contexto da escolha inicial e da evasão de curso universitário. Revista Brasileira de Orientação Profissional, 9 (2), 31-44.

Blustein, D. L.; Walbridge, M. M.; Friedlander, M. L. \& Palladino, D. E. (1991). Career development: contributions of psychological separation and parental attachment to the career development process. Journal of Counseling Psychology, 38 (1), 3940.

Bohslavsky, R. (2007). Orientação Vocacional: a estratégia clínica. (12a . ed.). São Paulo: Martins Fontes (Original publicado em 1977).

Carvalho, M. \& Taveira, M. C. (2009). Influência de pais nas escolhas de carreira dos filhos: visão de diferentes atores. Revista Brasileira de Orientação Profissional, 10 (2), 33-41.

Destri, F. S. (1996). Relações entre pais e filhos adolescentes e o processo de escolba profissional. Dissertação de Mestrado, Instituto de Filosofia e Ciências Humanas, Universidade Federal do Rio Grande do Sul, Rio Grande do Sul.

Dias, M. L. (1995). Família e escolha profissional Em Bock, A. M. B. \& cols. A escolha profissional em questão (pp. 71-92). São Paulo: Casa do Psicólogo.

Duarte, V. D.; Melo-Silva, L. L.; Santos, M. A \& Bonfim, T. A. (2005). A influência familiar na escolha profissional dos filhos, na perspectiva de mães de clientes em processo de orientação profissional. Em Simon, C. P.; Melo-Silva, L. L. \& Santos, M. A (Orgs.). Formação em psicologia: desafios da diversidade na pesquisa e na prática (pp. 285-306). São Paulo: Vetor.

Eigen, C.A.; Hartman, B.W \& Hartman, P.T. (1987). Relations between family interaction patterns and career indecision. Psychological Reports, 60, 8794.

Filomeno, K. (1997). Mitos familiares e a escolha profissional: uma visão sistêmica. São Paulo: Vetor.

Gonçalves, C. M. (1998). A influência da família no desenvolvimento vocacional de adolescentes e jovens. Em Anais da $5^{a}$. Conferência Bienal da EARA. Budapeste, Hungria.

Gonçalves, C.M \& Coimbra, J.L. (2007). O papel dos pais na construção de trajectórias vocacionais dos seus Filhos. Revista Brasileira de Orientação Profissional, 8 (1), 1-17. 
Guichard, J.; Huteau, M. (2001). Psicologia da Orientação. Lisboa: Instituto Piaget.

Hartung, P.J.; Porfeli, E.J.; Vondracek, F.W. (2005). Child vocational development: A review and reconsideration. Journal of Vocational Behavior, 66, 385-419.

Kracke, B. (1997). Parental behaviors and Adolescents' Career Exploration. The Career Development Quarterly, 45, 341-350.

Lent, R. W., Brown, S. D., Talleyrand, R., McPartland, E. B., Davis, T., Chopra, S., Alexander, M., Suthakaran, V., \& Chai, C. (2002). Career choice barriers, supports, and coping strategies: College students' experiences. Journal of Vocational Behavior, 60(1), 61-72.

Levenfus, R. S. \& Nunes, M. L. T. (2002a). Jovens com perda parental lidando com o luto e com a escolha profissional. Em Levenfus, R. S. \& Soares, D. H. P (Org.). Orientação vocacional ocupacional: novos achados teóricos, técnicos $e$ instrumentais para a clinica, a escola e a empresa (pp.163-178). Porto Alegre: Artmed.

Levenfus, R. S. \& Nunes, M. L. T. (2002b). O temor da escolha errada em filhos de pais separados. Em Levenfus, R. S. \& Soares, D. H. P (Org.). Orientação vocacional ocupacional: novos achados teóricos, técnicos e instrumentais para a clínica, a escola e a empresa (pp. 149-161). Porto Alegre: Artmed.

Levenfus, R. S. \& Nunes, M. L. T. (2002c). A nãoescolha profissional em jovens simbiotizados. Em Levenfus, R. S. \& Soares, D. H. P. (Org). Orientação vocacional ocupacional: novos achados teóricos, técnicos e instrumentais para a clinica, a escola e a empresa (pp. 179-192). Porto Alegre: Artmed.

Lopez, G. F. (1989). Current family dynamics, trait anxiety, and academic adjustment: test of a family-based model of vocational identity. Journal of Vocational Behavior, 35, 76-87.

Lopez, G.F \& Andrews, S. (1987). Career indecision: A family systems perspective. Journal of Counseling and Development, 65, 304-307.

Melo-Silva, L. L.; Silva, L. M. \& Venturini, P. F. (2005). Cartas que dizem muito: pais e filhos na orientação profissional. Em Simon, C. P; MeloSilva, L. L \& Santos, M. A. (Orgs). Formação em psicologia: desafios da diversidade na pesquisa e na prática (pp. 285-320). São Paulo: Vetor.

O'Brien, K. (1996). The influence of psychological separation and parental attachment on the career development of adolescent women. Journal of Vocational Behavior, 48, 257-274.

O'Brien, K. M.; Friedman, S. M.; Tipton, L. C. \& Linn, S. G. (2000). Attachment, separation, and women's vocational development: A longitudinal analysis. Journal of Counseling Psychology, 47, 301315.

Oliveira, I. M. D. A. \& Dias, C. M. S. B. (2001). Família pós-moderna, construção de subjetividade e escolha profissional. Em Anais do IV Simpósio Brasileiro de Orientação Vocacional e Ocupacional; I Encontro de Orientadores Profissionais do Mercosul. São Paulo: Vetor.

Oliveira, I. M. D. A. (2005). De quem é o vestibular? Articulações entre a família e a escolha profissional. Em Vasconcelos, Z. B. \& Oliveira, I. D. (Orgs). Orientação vocacional: alguns aspectos teóricos, técnicos e práticos (pp. 61-77). São Paulo: Vetor.

Otto, L. B. (2000). Youth Perspectives on Parental Career Influence. Journal of Career Development, 27 (2), 111-118.

Palmer, S. \& Cochran, L. (1988). Parents as agents of career development. Journal of Counseling Psychology, 35, 71-76.

Pinto, H. R. \& Soares, M. C. (2001). Influência parental na carreira: evolução de perspectivas na teoria, na investigação e na prática. Psychologica, 26, 135149.

Pinto, H. R. \& Soares, M. C. (2002). Influência parental no desenvolvimento vocacional dos adolescentes. Revista Portuguesa de Psicologia, 36, 111-137.

Pompemayer, C. (1999). O processo de luto do adolescente em relação às imagos parentais relacionado com a escolha de uma profissão. Dissertação de Mestrado, Instituto de Psicologia, Universidade Federal do Rio Grande do Sul.

Roe, A. (1957). Early determinants of vocational choice. Journal of Counseling Psychology, 4, 212-217.

Romanelli, G. (1995). Autoridade e poder na familia. Em Carvalho, M. C. B. (Org.). A família contemporânea em debate (pp. 73-88). São Paulo: EDUC.

Romanelli, G. (2003), Questões teóricas e metodológicas nas pesquisas sobre família e escola. Em Zago, N., Carvalho, M. P., \& Vilela, R. A. T. Itinerários de pesquisa: perspectivas qualitativas em Sociologia da Educação (pp. 245-264). Rio de Janeiro: DP\&A.

Savickas, M. L. (1995). Current theoretical issues in vocational psychology: convergence, divergence, and schim. Em WALSH, W. B.; OSIPOW, S. H. Handbook of vocational pychology: theory, research, and practice (pp. 1-34). New Jersey: LEA.

Schmitt-Rodermund, E., \& Vondracek, F. W. (1999). Breadth of interests, exploration, and identity 
development in adolescence. Journal of Vocational Behavior, 55, 298-317.

Schulenberg, J. E., Vondracek, F. W. \& Crouter A. C. (1984). The influence of the family on Vocational Development. Journal of Marriage and the family .46 (1), 129-143.

Scott, D. J. \& Church. (2001). Separation/attachment theory and career decidedness and commitment: effects of parental divorce. Journal of Vocational Behavior, 58, 328-347.

Soares-Lucchiari, D. H. (1997a). O ideal de Ego e o projeto de futuro profissional dos adolescentes. Em Levenfus, R. S. (Org). Psicodinâmica da escolha profissional (pp. 47-95). Porto Alegre: Artes Médicas.

Soares-Lucchiari, D. H. (1997b). Uma abordagem genealógica a partir do genoprofissiograma e do Teste dos Três Personagens. Em Levenfus, R. S. (Org.). Psicodinâmica da escolha profissional (pp. 135160). Porto Alegre: Artes Médicas.

Soares, D. H. P. \& Knabem, A. (2005). Reunião de pais no POPI: encontro entre pais e filhos. Em Soares, D. H. P.; Oliveira, E. N. POPI: programa de orientação profissional intensivo: outra forma de fazer orientação profissional (pp. 41-50). São Paulo: Vetor.

Soares, M. C. \& Pinto, H. R. (2004). Envolver os pais nas práticas de orientação vocacional. Em Separata da obra Desenvolvimento vocacional ao longo da vida: fundamentos, princípios e orientações (pp. 252257). Coimbra: Almedina.
Vignoli, E.; Croit-Belz, S.; Chapeland, V.; Fillipis, A. \& Garcia, M. (2005). Career exploration in adolescents: the role of anxiety, attachment and parenting stile. Journal of Vocational Behavior, 67 (2), 153-168.

Vondracek, F. W. (2004). Avaliação das relações pessoa-contexto. Em Leitão, L. M. Avaliação Psicológica em Orientação Escolar e Profissional (pp. 429-451). Coimbra: Quarteto.

Young, A. R.; Friesen, J. D. \& Borycki, B. (1994). Narrative structure and parental influence in career development. Journal of Adolescence, 17, 173-191.

Young, A. R.; Marshall S.; Domene J. F.; Arato-Bolivar, J., Hayoun R., Marshall E., Zaidman-Zait, A \& Valach, L. (2005). Relationship, communication, and career in the parent-adolescent projects of families with and without challenges. Journal of Vocational Behavior, 68(1), 1-23.

Young, R. A; Valach, L.; Ball, J.; Paseluikho, M. A.; Wong, Y. S. \& Devries, R. J.; Mclean, H.; Turkel, H. (2001). Career development in adolescence as a family project. Journal of Counseling Psychology, 48(2), 190-202.

Whiston, S. C. \& Keller, B. K. (2004). The influences of the family of origin on career development: a review and analysis. The Counseling Psychologist, 32(4), 493-568.

Recebido em outubro de 2010 Reformulado em janeiro de 2011 Aprovado em fevereiro de 2011

Sobre as autoras:

Lucy Leal Melo-Silva é psicóloga, docente da Graduação e da Pós-Graduação em Psicologia da Faculdade de Filosofia, Ciências e Letras de Ribeirão Preto (FFCLRP-USP). Membro da Associação Brasileira de Orientadores Profissionais (ABOP) e da International Association Educational Vocacional Guidance (IAEVG). Editora da Revista Brasileira de Orientação Profissional. Autora de livros na área da Orientação Profissional e Formação em Psicologia. Pesquisadora CNPq.

Fabiana Hilário de Almeida é Psicóloga, Mestre (Capes) e Doutoranda (CNPq) em Psicologia pela Faculdade de Filosofia, Ciências e Letras de Ribeirão Preto, da Universidade de São Paulo (FFCLRP-USP). Pesquisadora na área da Orientação Vocacional/Profissional, com ênfase em influência parental, orientação de pais com perspectiva psicodinâmica e Grupo Operativo.

Este estudo é parte dos dados da pesquisa de Mestrado da primeira autora (Almeida, 2009) orientada pela segunda, com financiamento da Coordenação de Aperfeiçoamento de Pessoal de Nível Superior (CAPES). 